\title{
Mining Late Embryogenesis Abundant (LEA) Family Genes in Cleistogenes songorica, a Xerophyte Perennial Desert Plant
}

\author{
Blaise Pascal Muvunyi ${ }^{\mathbb{D}}$, Qi Yan, Fan Wu, Xueyang Min, Zhuan Zhuan Yan, Gisele Kanzana, \\ Yanrong Wang * and Jiyu Zhang * \\ State Key Laboratory of Grassland Agro-ecosystems; Key Laboratory of Grassland Livestock Industry \\ Innovation, Ministry of Agriculture; College of Pastoral Agriculture Science and Technology, \\ Lanzhou University; Lanzhou 730000, China; muvunyi14@lzu.edu.cn (B.P.M.); yanq16@lzu.edu.cn (Q.Y.); \\ wuf15@lzu.edu.cn (F.W.); minxy15@lzu.edu.cn (X.M.); yanzhzh16@lzu.edu.cn (Z.Z.Y.); \\ giskanzana@gmail.com (G.K.) \\ * Correspondence: yrwang@lzu.edu.cn (Y.W.); zhangjy@lzu.edu.cn (J.Z.); Tel.: +86-931-891-4051 (Y.W.); \\ +86-138-933-29958 (J.Z.)
}

Received: 19 September 2018; Accepted: 23 October 2018; Published: 1 November 2018

\begin{abstract}
Plant growth and development depends on its ability to maintain optimal cellular homeostasis during abiotic and biotic stresses. Cleistogenes songorica, a xerophyte desert plant, is known to have novel drought stress adaptation strategies and contains rich pools of stress tolerance genes. Proteins encoded by Late Embryogenesis Abundant (LEA) family genes promote cellular activities by functioning as disordered molecules, or by limiting collisions between enzymes during stresses. To date, functions of the $L E A$ family genes have been heavily investigated in many plant species except perennial monocotyledonous species. In this study, 44 putative $L E A$ genes were identified in the $C$. songorica genome and were grouped into eight subfamilies, based on their conserved protein domains and domain organizations. Phylogenetic analyses indicated that C. songorica Dehydrin and LEA_2 subfamily proteins shared high sequence homology with stress responsive Dehydrin proteins from Arabidopsis. Additionally, promoter regions of CsLEA_2 or CsDehydrin subfamily genes were rich in G-box, drought responsive (MBS), and/or Abscisic acid responsive (ABRE) cis-regulatory elements. In addition, gene expression analyses indicated that genes from these two subfamilies were highly responsive to heat stress and ABA treatment, in both leaves and roots. In summary, the results from this study provided a comprehensive view of $C$. songorica $L E A$ genes and the potential applications of these genes for the improvement of crop tolerance to abiotic stresses.
\end{abstract}

Keywords: Cleistogenes songorica; LEA proteins; gene expression analysis; abiotic stresses

\section{Introduction}

Abiotic stresses from increasing temperature or salinity can disrupt optimal plant performance and cause significant crop yield losses [1]. To maintain proper homeostasis for normal growth, plants have evolved multiple ways to combat harsh environments by mobilizing a wide spectrum of stress responsive genes [2]. For example, proteins encoded by the late embryogenesis abundant (LEA) family genes are known to play defensive roles in plants during abiotic stresses [3,4]. The $L E A$ family genes were first studied in cotton seed at the late phases of seed development [4]. The $L E A$ family genes were later identified in various tissues of many other plant species and the proteins encoded by these genes were shown to be important during cold, drought and/or high salinity stresses [5,6]. LEA proteins are not plant specific, they are also found in invertebrates, fungi and bacteria [7,8]. Typical LEA 
proteins are highly hydrophilic due to high contents of charged amino acid residues, as well as amino acids like threonine, serine and alanine residues in their sequences [9]. It was suggested that LEA proteins have molecular shield functions [10] and are capable of abating protein aggregation and preventing enzyme degradation [11], thereby promoting proper cellular homeostasis during stresses $[8,12]$. LEA proteins are also flexible proteins which can undergo conformational changes and interact with other macromolecules including proteins, membranes and/or nucleic acids during different adverse stress conditions [10].

LEA proteins are divided into at least eight distinct subfamilies, based on their conserved protein domains in the Pfam database: LEA (1-6), Dehydrin and Seed Maturation Protein (SMP) [13]. Motif structures within subfamily genes are mostly conserved, except the genes in the LEA_2/LEA5C subfamily [9]. In addition, proteins in the LEA_2/LEA5C subfamily are known to have other non-canonical LEA protein properties like high hydrophobicity and at least one atypical LEA domain known as Water stress and Hypersensitive response (WHy) domain. The presence of atypical LEA domain(s) in LEA proteins indicate that these proteins may function differently from typical LEA proteins [14-16]. Proteins in the Dehydrin subfamily are featured with at least one K-segment, a 15 amino acid residue rich in lysine (i.e., EKKGIMDKIKEKLPG) and can function like chaperones to protect peripheral membrane and proteins during dehydration [2,17-20]. Numerous earlier studies have demonstrated that the $L E A$ family genes are potential abiotic stress responsive genes, important for enhancing plant stress tolerance. For instance, transgenic Arabidopsis [21,22], maize [23], alfalfa [24] bacteria [25], yeast and tobacco [26] expressing different $L E A$ genes exhibited improved abiotic stress tolerance compared with their respective wild-type plant, bacteria or yeast.

C. songorica is a xerophyte $\mathrm{C} 4$ desert plant distributed widely in the wild lands in the northwest part of China, with an annual precipitation of about $100 \mathrm{~mm}$ [27]. Previous genome-wide surveys of $L E A$ family genes were done for multiple plant species except perennial monocotyledonous species. In this study, we investigated the $L E A$ family genes in $C$. songorica and analyzed the responses of four selected LEA genes to heat stress or abscisic acid (ABA) treatment in leaves and shoots. Results from this study provide new information on the evolution of the LEA family proteins, protein structures and potential applications of these genes for the improvement of crop tolerance against abiotic stresses.

\section{Results}

\subsection{Identification of CsLEA Genes and Phylogenetic Analysis}

A total of 44 putative C. songorica LEA proteins were identified in this study (Table S1). These proteins were named from CsLEA1 to CsLEA44 and grouped into eight different subfamilies (Figure 1): CsLEA_1, CsLEA_2/LEA5C (Battaglia classification), CsLEA_3, CsLEA_4, CsLEA_5, CsLEA_6, SMP and Dehydrin, based on their Pfam conserved protein domains and their homology with the published LEA proteins of $A$. thaliana [28]. Two atypical LEA stress related domains, Water Stress and Hypersensitive response (WHy) and LEA14-like desiccation related protein (COG5608), were detected in the proteins from CsLEA_2 subfamily (Figure S1).

\subsection{Structures, Physiochemical Properties and Subcellular Localizations of CsLEA Proteins}

Most proteins within the same family exhibited similar structures and properties (Table S1). Over one third of the CsLEA proteins were classified as unstable proteins with an instability index value higher than 40 . Furthermore, this property varied significantly among the proteins within the Dehydrin subfamily, ranging from 3.83 to 56.11. All the proteins in the LEA_5 subfamily showed instability index values greater than 47 and were considered as the most unstable and/or potentially disordered proteins [29-31]. The GRAVY (grand average of hydropathicity index) values of more than 90\% CsLEA proteins were below 0, stressing that CsLEA proteins are likely to have low hydrophobicity features. CsLEA_2 subfamily proteins were the most hydrophobic proteins, while Cs_LEA5 proteins 
were the highest hydrophilic proteins. These results are consistent with previous studies $[28,32]$ and reinforce the structural disordered properties of LEA proteins by which they are capable of interacting with other molecules and mitigating the collision of enzymes during plant stress conditions [11]

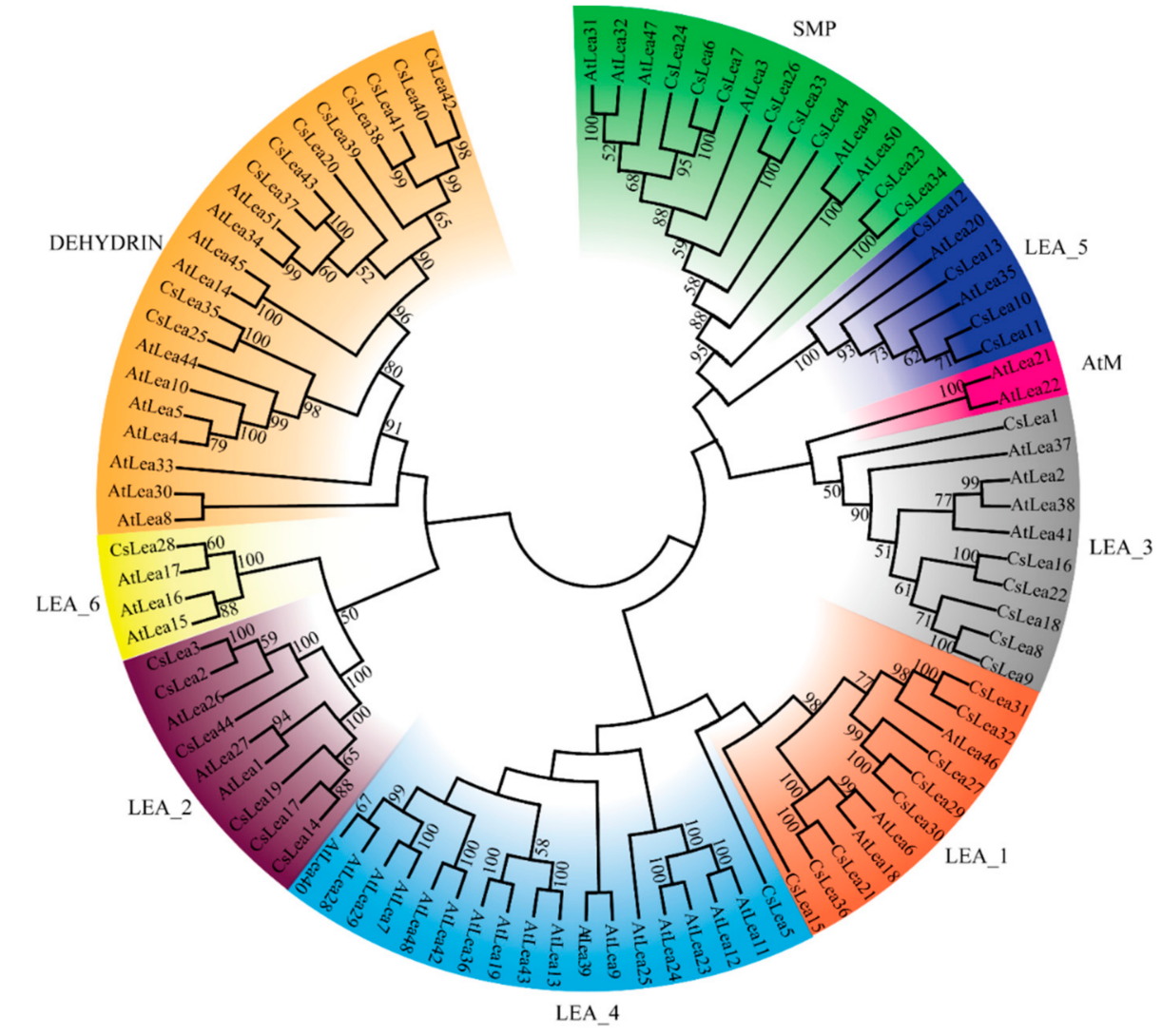

Figure 1. Phylogenetic analysis of $C$. songorica LEA proteins. Full-length amino acid sequences of the 44 CsLEA proteins were analyzed using the unrooted method in the ClustalW software.

\subsection{Gene and Motif Structure Analyses}

LEA genes within the same subfamily showed similar exon and intron architectures (Figure 2, right panel). Further investigation of structures of paired genes at the short-end branches in the phylogenetic tree revealed that six of them (e.g., CsLEA 43-37, 35-25, 2-3, 8-9, 23-34 and 6-7) might have experienced exon-intron gain/loss events during their evolutionary history. Similar situations have been reported for Brassica LEA genes [21,33]. In total, 18 motifs were identified in 43 CsLEA proteins (Figure 2, left panel). No motif was found in CsLEA28 protein. Except for LEA_2 and LEA_3 subfamily proteins, motif structures and compositions were nearly identical among the proteins in the same subfamily, but differed significantly between the proteins belonging to different subfamilies, implying functional specificities of different CsLEA subfamily proteins $[14,34]$. 


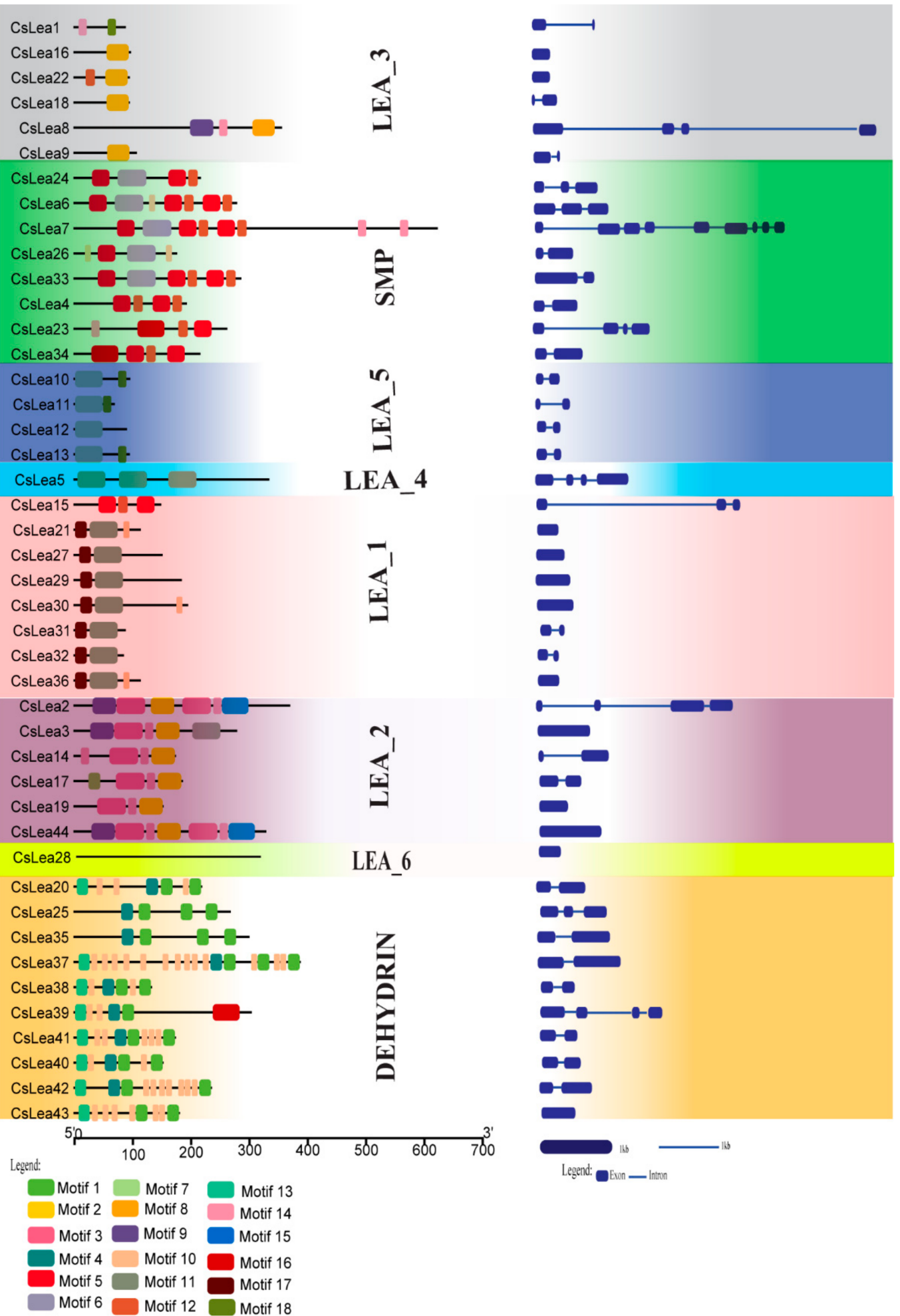

Figure 2. Motif structure and exon-intron organizations of the 44 CsLEA genes. The 18 motifs discovered in this study are shown on these CsLEA genes (left). The blue boxes represent exons and the blue lines represent introns (right). 


\subsection{Sequence Alignment of C. Songorica and Arabidopsis Dehydrin Proteins}

Multiple sequence alignment using C. songorica Dehydrin protein sequences and their Arabidopsis counterparts revealed the conservation stress response related segments including $\mathrm{Y}, \mathrm{K}$ and $\mathrm{S}$ segments (YKS) in C. songorica Dehydrin proteins (Figure 3).
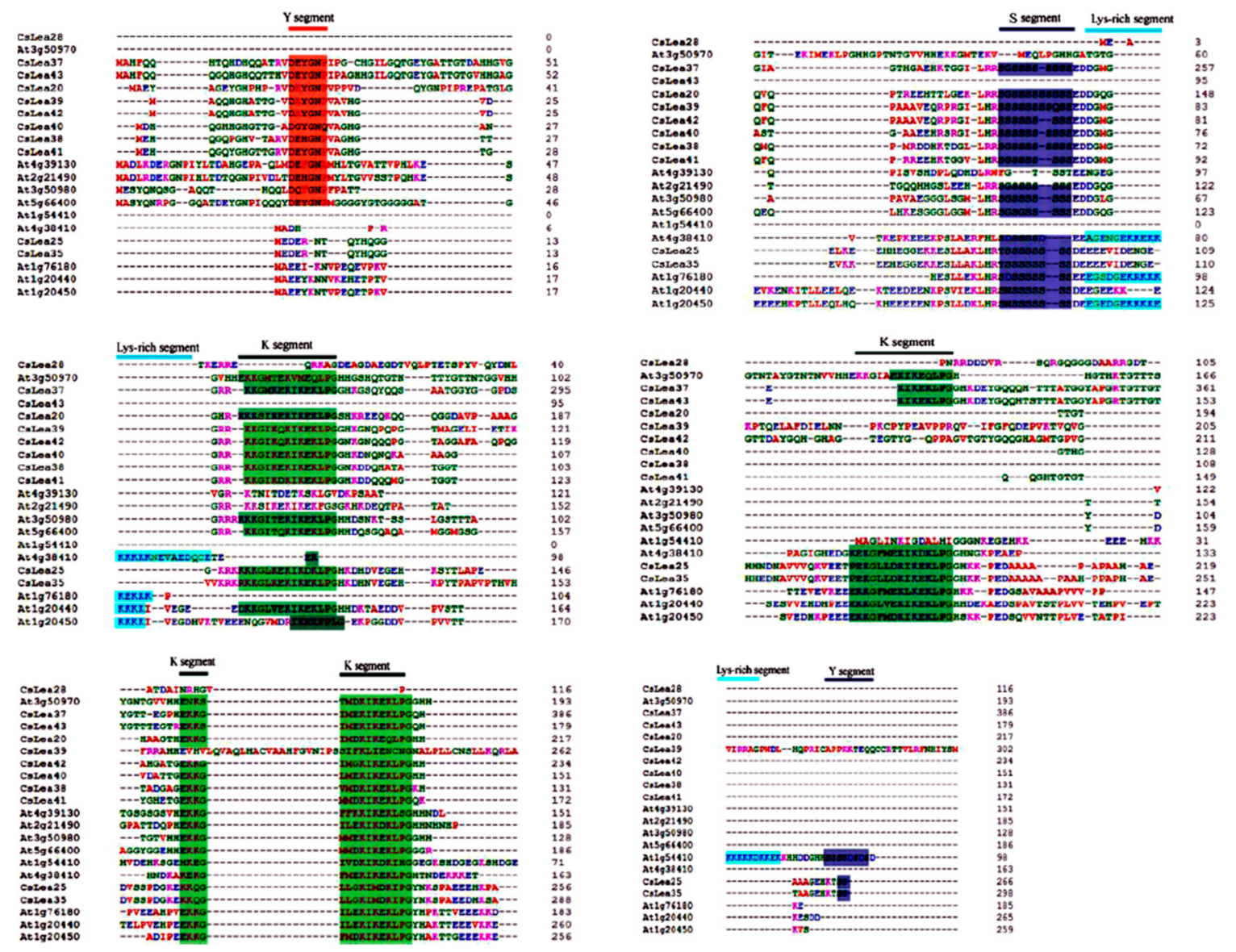

Figure 3. Multiple sequence alignment using C. songorica and Arabidopsis Dehydrin protein sequences. The identified Y segment, K segment and S segment are indicated by different colors. Y segment = red, $\mathrm{K}$ segment = green and S segment = purple.

\subsection{Cis-Regulatory Element in C. Songorica LEA Gene Promoters}

Cis-regulatory elements control expression patterns of stress responsive genes in various tissues and organs. These elements are located upstream of gene coding sequences and provide binding sites for transcription factors (TFs) [35]. More than three G-box cis-elements were recorded for each Dehydrin, LEA_2 and SMP genes and nearly more than two MBS elements were detected for each Dehydrin and LEA_2 subfamily gene (Table 1). 
Table 1. Stress-related cis-regulatory elements in 44 C. songorica LEA gene promoters.

\begin{tabular}{|c|c|c|c|c|c|}
\hline \multirow{4}{*}{$\begin{array}{c}\text { CsLEA } \\
\text { Subfamilies }\end{array}$} & \multirow{4}{*}{ Gene Names } & \multicolumn{4}{|c|}{ Functional $c i s$-Element Names and Sequences } \\
\hline & & MBS (CGGTC) & $\begin{array}{c}\text { G-Box } \\
\text { (GTGCAT/CACGAC) }\end{array}$ & $\begin{array}{c}\text { ABRE } \\
\text { (GACACGTACGT) }\end{array}$ & CGTCA Motif \\
\hline & & \multicolumn{4}{|c|}{ Functions } \\
\hline & & $\begin{array}{l}\text { Drought Responsive } \\
\text { (MYB Binding Site) }\end{array}$ & Light Responsive & $\begin{array}{c}\text { Abscisic } \\
\text { Acid Responsive }\end{array}$ & MeJA Responsive \\
\hline \multirow{5}{*}{ LEA_1 } & CsLEA29 & 3 & 1 & 1 & 0 \\
\hline & CsLEA30 & 2 & 3 & 1 & 4 \\
\hline & CsLEA31 & 4 & 1 & 1 & 0 \\
\hline & CsLEA32 & 2 & 2 & 1 & 0 \\
\hline & CsLEA36 & 4 & 5 & 2 & 2 \\
\hline \multirow{6}{*}{ LEA_2 } & CsLEA2 & 2 & 1 & 0 & 3 \\
\hline & CsLEA3 & 0 & 3 & 2 & 2 \\
\hline & CsLEA14 & 2 & 6 & 1 & 0 \\
\hline & CsLEA17 & 3 & 9 & 3 & 0 \\
\hline & CsLEA19 & 5 & 0 & 0 & 1 \\
\hline & CsLEA44 & 0 & 0 & 0 & 2 \\
\hline \multirow{6}{*}{ LEA_3 } & CsLEA1 & 4 & 2 & 0 & 2 \\
\hline & CsLEA16 & 1 & 2 & 0 & 3 \\
\hline & CsLEA22 & 1 & 3 & 1 & 3 \\
\hline & CsLEA18 & 8 & 3 & 3 & 0 \\
\hline & CsLEA8 & 0 & 7 & 1 & 2 \\
\hline & CsLEA9 & 3 & 0 & 0 & 0 \\
\hline LEA_4 & CsLEA5 & 1 & 5 & 4 & 1 \\
\hline \multirow{4}{*}{ LEA_5 } & CsLEA10 & 0 & 2 & 0 & 1 \\
\hline & CsLEA11 & 0 & 3 & 0 & 3 \\
\hline & CsLEA12 & 2 & 7 & 1 & 1 \\
\hline & CsLEA13 & 2 & 1 & 3 & 5 \\
\hline LEA_6 & CsLEA28 & 0 & 9 & 5 & 3 \\
\hline \multirow{10}{*}{ SMP } & CsLEA24 & 0 & 4 & 1 & 0 \\
\hline & CsLEA6 & 2 & 0 & 2 & 0 \\
\hline & CsLEA7 & 2 & 6 & 0 & 0 \\
\hline & CsLEA26 & 1 & 5 & 1 & 1 \\
\hline & CsLEA33 & 0 & 5 & 1 & 4 \\
\hline & CsLEA4 & 2 & 1 & 0 & 0 \\
\hline & CsLEA23 & 2 & 1 & 0 & 0 \\
\hline & CsLEA34 & 1 & 4 & 0 & 1 \\
\hline & CsLEA42 & 0 & 3 & 1 & 2 \\
\hline & CsLEA43 & 0 & 0 & 1 & 5 \\
\hline \multirow{10}{*}{ Dehydrin } & CsLEA20 & 4 & 5 & 0 & 0 \\
\hline & CsLEA25 & 4 & 2 & 0 & 1 \\
\hline & CsLEA35 & 3 & 8 & 2 & 1 \\
\hline & CSLEA37 & 0 & 6 & 3 & 4 \\
\hline & CsLEA38 & 2 & 10 & 2 & 3 \\
\hline & CsLEA39 & 3 & 1 & 0 & 1 \\
\hline & CsLEA41 & 2 & 0 & 1 & 2 \\
\hline & CsLEA40 & 0 & 2 & 0 & 1 \\
\hline & CsLEA42 & 0 & 3 & 1 & 2 \\
\hline & CsLEA43 & 0 & 0 & 1 & 5 \\
\hline
\end{tabular}

\subsection{Chromosomal Mapping of CsLEA Genes}

C. songorica genome has in total twenty chromosomes. Positions of the 44 CsLEA genes on 15 different $C$. songorica chromosomes were estimated (Figure 4). Genes from the same subfamily were mostly found on different chromosomes, suggesting a strategy to exert their functions across the whole C. songorica genome. However, genes in the LEA_5 and Dehydrin subfamily were mostly found in clusters on the 14th, 15th and 18th chromosome.

\subsection{Gene Expression Analysis qRT-PCR Validation}

The expression levels of the CsLEA 14, CsLEA 19, CsLEA 37 and CsLEA 38 genes were induced after $24 \mathrm{~h}$ of ABA or heat treatment but were not tissue specific (Figure 5). To validate results from expression profile analysis, qRT-PCR was carried out for CsLEA 14, CsLEA 19 (from the LEA_2 subfamily) and for CSLEA37 and CSLEA 38 (from the Dehydrin subfamily) as these genes showed a relatively high number of stress related cis acting elements and motifs. 
We carried out qRT-PCR analyses using CsLEA14 and CsLEA19 (LEA_2 subfamily), and CsLEA37 and CsLEA 38 (Dehydrin family). Results showed that after $24 \mathrm{~h}$ heat treatment the expression levels of these four genes up-regulated by 156.5 (CsLEA 19), 95.8 (CsLEA14), 52.6 (CsLEA38) and 14.6 fold (CsLEA37) in $C$. songorica leaves compared with the untreated plant leaf samples. The expression levels of these four genes were slightly up-regulated after the ABA treatment, especially CsLEA 38 (14.6 fold, Figure 6).

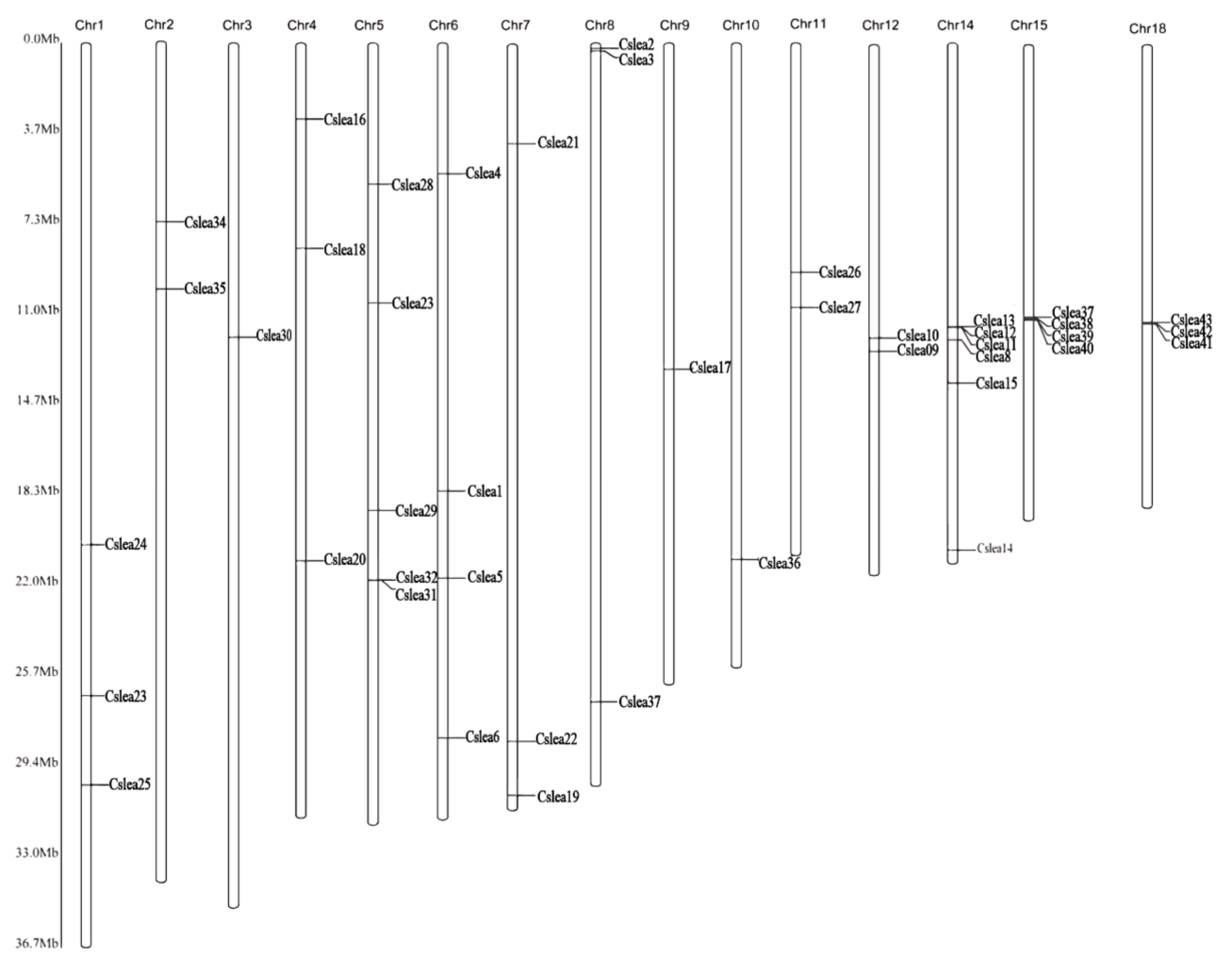

Figure 4. Locations of the 44 CsLEA genes on 15 chromosomes of C. songorica.

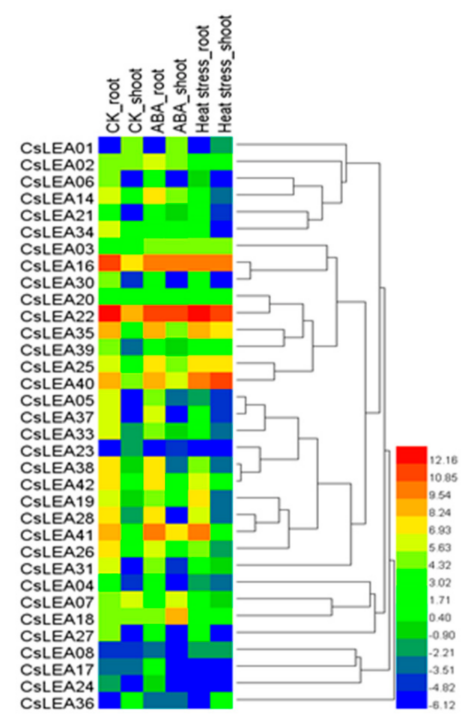

Figure 5. Hierarchical clustering of CsLEA gene expression profiles in root and shoot tissues after $24 \mathrm{~h}$ heat or ABA treatment. The log transformed values for the relative expressions of CSLEA genes were used for the hierarchical clustering analysis. The blue scale means low transcript expression and the red scale means high transcript expression. 

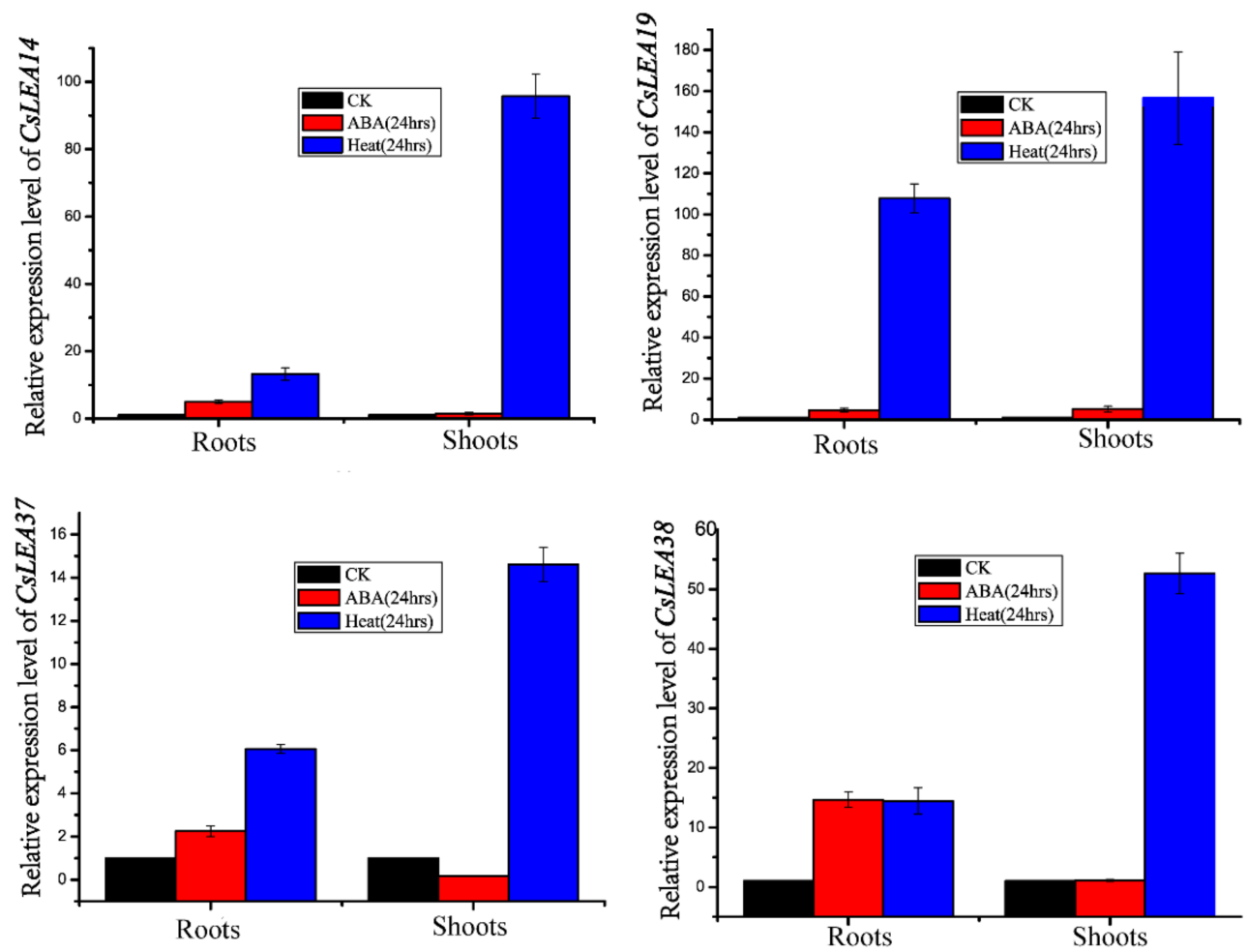

Figure 6. Hierarchical clustering of CsLEA gene expression profiles in root and shoot tissues after $24 \mathrm{~h}$ heat or ABA treatment. The log transformed values for the relative expressions of CsLEA genes were used for the hierarchical clustering analysis. The blue scale means low transcript expression and the red scale means high transcript expression.

\section{Discussion}

\subsection{Phylogeny Analysis and Protein Sequence Analysis}

Genome surveys of LEA subfamily proteins (e.g., LEA_1 to LEA_6, SMP and DEHYDRIN) were done for A. thaliana [28], rice [36] and maize [37]. C. songorica is a perennial monocotyledonous desert plant with a high tolerance for drought stress. Investigation of stress responsive proteins encoded by $L E A$ family genes in a desert plant should benefit crop improvement for drought and other abiotic stresses. Phylogenetic analysis grouped the CsLEA proteins into eight different subfamilies. Several C. songorica and Arabidopsis Dehydrin subfamily proteins were clustered together with high bootstrap values, which implied potential significant functional similarities between $C$. songorica and Arabidopsis DEHYDRIN proteins. Many of the Arabidopsis Dehydrin proteins are known as stress regulatory proteins such as RAB18 (AtLea51) and COR47 (AtLea4), two ABA and cold inducible proteins [38,39], ERD14 (AtLea4) and ERD10 (AtLea5), two disordered chaperon proteins [40] and Dehydrin Xero2 (AtLea33), a disordered cold responsive protein with membrane binding activity [41].

Sequence alignment using CsDehydrin proteins and their Arabidopsis counterparts revealed that all C. songorica Dehydrin proteins contained YKS segments but lacked the lysine rich segment. The K segment is critical for the formation of structural disordered alpha-helical compounds that can enhance bindings between proteins and their targeted molecules [10,42]. The presence of the $\mathrm{K}$ segment in C.songorica DEHYDRIN proteins emphasizes their role in limiting aggregation of molecules and thence promoting proper cellular homeostasis during dehydration stresses [11]. Additionally, the detection of the $\mathrm{S}$ segment in the $C$. songorica DEHYDRIN protein also suggests their implication in enhancing plant tolerance against abiotic stresses through protein phosphorylation, as previous studies indicated that the $S$ segment participates in calcium binding through protein phosphorylation [43]. The findings above support the fact that disordered LEA proteins are flexible 
proteins, capable of adjusting their conformation to maintain proper cellular homeostasis during detrimental stress conditions [43,44].

\subsection{Protein Domain Analysis}

Two additional non-LEA conserved protein domains that are associated with stress response were detected in the CsLEA_2 subfamily proteins (Supplementary Figure S1). At least one WHy (Water stress and Hypersensitive response) $[15,16]$ and one COG5608 domain (LEA14-like desiccation related protein) was spotted within each single protein sequence from the CsLEA_2 subfamily. The COG5608 domain was previously detected in the Arabidopsis LEA14 protein, a well characterized abiotic stress marker protein, which suggests that the CsLEA_2 subfamily proteins may function similarly to Arabidopsis LEA14 protein (Atlea1). On the other hand, a thorough functional characterization of the WHy domain has only been elucidated in a few bacterial genes, dwhy1 [15] and drwh [45]. Studies in vivo indicated that dwhy1 confers cold and freeze damage resistance. Furthermore, in E. coli, the function of $d r w h$ is related to oxidative stress tolerance and salinity stresses. Silencing this gene triggered reduced activity of antioxidant enzymes such as lactate dehydrogenase (LDH) malate dehydrogenase (MDH) $[15,45]$. All the CsLea_2 subfamily genes contained the WHy domain which could explain the functional importance of this domain during low water availability in a typical desert grass, $C$. songorica.

\subsection{C. songorica Gene Promoter and Gene Expression Analysis}

ABA and stress responsive cis-regulatory elements, such as ABRE, MBS/MYB and G-Box were found to be abundant in the promoters of $C$. songorica Dehydrin and the $L E A \_2$ subfamilies genes. These regulatory elements are known to provide binding sites for transcription factors like ABEF (a member of the bZIPTFs family), BHLH and ERF for the transcription of downstream stress responsive genes [46]. Expression analysis of CsLEA37 and CsLEA38 (DEHYDRIN genes), and CsLEA14 and CSLEA19 (LEA_2 subfamily genes) with qRT-PCR indicated that the expression levels of these four genes in root and shoot tissues were significantly up-regulated after the drought or ABA treatment.

The relevant role of DEHYDRIN or the LEA_2 subfamily proteins during plant stress tolerance has been reported in earlier studies using various transgenic plants. For example, transgenic tobacco plant overexpressing the CaLEA6 gene showed an enhanced dehydration and salt tolerance [47]. Additionally, sweet potato plants overexpressing the IbLEA14 gene exhibited an improved salinity and dehydration tolerance [48]. A Foxtail millet plant overexpressing the SiLEA4 gene displayed salt and drought resilience [49]. For DEHYDRIN proteins, transgenic Arabidopsis plant expressing a Dehydrin gene from an olive showed an enhanced osmotic stress tolerance [50]. Similarly, a wheat Dhn-5 gene increased salinity and dehydration stress tolerance in transgenic Arabidopsis plants [51]. C. songorica DEHYDRIN and LEA_2 gene transcripts accumulation during water deficit and ABA treatment, reinforcestheir functional importance under detrimental stress conditions.

\section{Materials and Methods}

\subsection{Mining LEA Genes in the C. Songorica Genome}

C. songorica $L E A$ genes were mined based on their protein sequence homology with the previously published A. thaliana [28], Oryza sativa (rice) [36] and Zea mays (maize) [37] LEA protein sequences. The published full length $A$. thaliana, rice and maize LEA protein sequences or coding sequences were retrieved from (https:/ / phytozome.jgi.doe.gov/pz/portal.html) [28,32]. The obtained LEA protein sequences were used as queries to blast search the whole $C$. songorica genome sequence retrieved from the BMK cloud: http:/ /www.biocloud.net/ using a local blast tool [52,53].

The resulting non-redundant sequences were further examined with the Hidden Markov Model available in the Pfam database (http://pfam.sanger.ac.uk/search) [13] and then submitted to the SMART database (http:/ / smart.embl-heidelberg.de/) [54] and the NCBI Conserved Domain Search 
database (http://www.ncbi.nlm.nih.gov/Structure/cdd/wrpsb.cgi) [55], respectively, to confirm CsLEA Pfam domain families. The obtained LEA nucleotide and protein sequences were then submitted to the Genbank to obtain respective accession numbers (Table S1).

\subsection{Multiple Sequence Alignment and Phylogenetic Analysis of CsLEA Family Proteins.}

The alignment of the $C$. songorica and Arabidopsis LEA protein sequences was performed using the ClustalW software [56] in the MEGA 6 program with a default parameter setting. After sequence alignment and pair-wise deletion of gaps as previously described [57], a phylogenetic tree was constructed using the Neighbor Joining (NJ) algorithm with bootstrap analysis of 1000 trials $[57,58]$. Multiple sequence alignment and sequence homology analysis of $C$. songorica and Arabidopsis Dehydrin proteins were performed using the ClustalW algorithm embedded in the DNAMAN version 6 program as instructed (Lynnon Corporation, Quebec, Canada).

\subsection{In Silico Analyses of CsLEA Proteins.}

Determination of GRAVY (grand average of hydropathicity index) values and pI (theoretical isoelectric point) were carried out by the ProtParam Tool (web.expasy.org/protparam/) [59]. Protein Prowler Subcellular Localization Predictor version 1.2 (http://bioinf.scmb.uq.edu.au/ pprowler_webapp_1--2/) 53 and TargetP1.1 (http:/ /www.cbs.dtu.dk/services/TargetP/) servers [60] were used to predict the subcellular locations of $C$. songorica LEA proteins. All of the prediction servers were run under the default settings. To determine the conserved motifs in different $C$. songorica and Arabidopsis LEA proteins, protein sequences were analyzed using MEME (The Multiple Expectation Maximization for Motif Elicitation) platform (http://alternate.meme-suite.org/) [61]. MEME parameters were then customized to detect a maximum of 40 motifs with a width covering 6 to 50 amino acid residues.

\subsection{Analysis of Cis-Regulatory Elements and Motifs}

Sequences of $2000 \mathrm{bp}$ from promoters of the 44 identified C. songorica LEA genes were analyzed for potential cis-regulatory elements and motifs by querying them through the PlantCARE database (http: //bioinformatics.psb.ugent.be/webtools/plantcare/html/) [62]. Stress- and ABA-related cis-regulatory elements, including MYB binding site (drought responsive) [63], G-box (light inducible) [64], ABRE (Abscisic acid responsive) [65] and CGTCA-motif (Methyl jasmonate responsive) [66] were recorded.

\subsection{Plant Material Preparation and Transcriptomic Data Analysis}

C. songorica seeds were sown in vermiculite medium supplied with $1 / 4$ diluted Hoagland's nutrient solution, $\mathrm{pH} 5.8$. Growth chamber conditions were set at $75-80 \%$ relative humidity, $30 / 28^{\circ} \mathrm{C}$ (day/night), and 16/8 h (day/night) light at $200 \mathrm{mmol}$ photons $\mathrm{m}^{-2} \mathrm{~s}^{-1}$. One-month old seedlings were treated with $40^{\circ} \mathrm{C}$ or with $100 \mu \mathrm{M}$ ABA. Root and shoot tissue samples were collected at 0 and $24 \mathrm{~h}$ post the treatment and kept at $-80^{\circ} \mathrm{C}$ till RNA extraction. Three root and shoot samples were collected from each treatment. Total RNA was isolated from the samples using the Shengong RNA isolation kit as instructed (Shengong Ltd., Shanghai, China). RNA pools were constructed following Illumina sequencing guidelines and then sequenced conferring to RNA-seq procedure. In total 24 million 250-bp raw reads were produced from the 12 samples. To eliminate adapter sequences from raw reads, the FASTX version 0.0.13 toolkit (http:/ / hannonlab.cshl.edu/fastxtoolkit/) was used. Additionally, the FastQC server tool (http:/ / www.bioinformatics.babraham.ac.uk/projects/fastqc/) was utilized to assess the quality of sequences. The resulting clean reads were aligned with the $C$. songorica genome by means of Tophat v.2.0.10 server (http:/ / tophat.cbcb.umd.edu/) [67] and the produced alignment files were used as Cufflinks inputs to create transcriptome assemblies [68]. The C. songorica gene expression levels were estimated based on fragments per kilobase of exon model per million mapped reads (FPKM) for root and shoot tissues. Following this, a random sampling model built on read count for each individual gene was applied to determine differentially expressed [69]. Gene expression levels 
were normalized with Pearson coefficients to generate hierarchical clustering with average linkage using HemI toolkit [70].

\subsection{Gene Expressions Analysis.}

The isolated RNA was then used to synthesize first strand cDNAs using an oligo dT primer and the cDNA synthesis kit (Shengong Ltd, Shanghai, China). The resulting cDNA samples were individually diluted to $100 \mathrm{ng} / \mu \mathrm{L}$ prior to qPCR using gene specific primers (Table S2). For each PCR reaction, three biological replicates with three technical replicates were each used. qPCR reactions were 40 cycles of $95^{\circ} \mathrm{C}$ for $5 \mathrm{~s}, 60^{\circ} \mathrm{C}$ for $15 \mathrm{~s}$, and $72{ }^{\circ} \mathrm{C}$ for $34 \mathrm{~s}$ using a SYBR Green Master (Shengong Ltd, Shanghai, China). The relative gene expression levels were determined using the comparative $\Delta \Delta C t$ method [71]. The expression level of the C. songorica GADPH gene was used as an internal control. Two-way analysis of variance and Duncan's multiple range test (DMRT) were used for multiple mean comparisons. SPSS (IBM Corp. 2013, IBM SPSS Statistics for Windows, Version 21.0, Armonk, NY, USA) was used to determine the significant differences between means $(p<0.005)$.

\section{Conclusions}

At a glance, this study methodically investigated at a genome wide level LEA proteins from a monocot perennial desert plant, Cleistogenes songorica. A total of 44 genes discovered were classified into eight different subfamilies and were found to be patchily spread over the $C$. songorica chromosomes. Analysis of the physio-chemical properties, motif and gene structure, homology and phylogenetic relationships detected that they were mostly similar within the same groups, but greatly differed among different subfamilies. Our study particularly explored CsLEA_2 and CsDEHYDRIN subfamilies proteins and elucidated their striking links with the regulatory mechanisms of plant abiotic stress tolerance. This study delivers a comprehensive summary of the evolution of the C. songorica LEA genes and some groundbreaking insights to the functional roles of this family that can be a critical foundation for crop abiotic tolerance improvement.

Supplementary Materials: Supplementary materials can be found at http:/ /www.mdpi.com/1422-0067/19/11/ $3430 /$ s1.

Author Contributions: Conceptualization, Y.W., J.Z., B.P.M. and X.M.; methodology, Y.W., J.Z., B.P.M., Z.Y.Y. and X.M.; software, B.P.M., Q.Y., Z.Y.Y. and F.W.; validation, B.P.M., X.M. and G.K.; formal analysis, B.P.M.; investigation, Q.Y. and J.Z.; resources, Y.W.; data curation, B.P.M., F.W.; writing-original draft preparation, B.P.M.; writing-review and editing, J.Z. and B.M.; visualization, G.K.; supervision, Y.W., project administration, Y.W., and G.K.; funding acquisition, Y.W.

Funding: This work was supported by the Program for Changjiang Scholars and Innovative Research Team in University (IRT_17R50), the National Natural Science Foundation of China (31572453), the Open Project Program of State Key Laboratory of Grassland Agro-ecosystems (SKLGAE201702) and the 111 project (B12002).

Acknowledgments: We thank Xin Shun Ding for his suggestions during manuscript preparation. We sincerely thank the anonymous reviewers for their critical comments and detailed suggestions for revision.

Conflicts of Interest: The authors declare no conflicts of interest.

\section{References}

1. Shahbaz, M.; Ashraf, M. Critical reviews in plant sciences improving salinity tolerance in cereals improving salinity tolerance in cereals. Crit. Rev. Plant Sci. 2013, 32, 237-249. [CrossRef]

2. Verma, G.; Dhar, Y.V.; Srivastava, D.; Kidwai, M.; Chauhan, P.S.; Bag, S.K.; Asif, M.H.; Chakrabarty, D. Genome-wide analysis of rice dehydrin gene family: Its evolutionary conservedness and expression pattern in response to peg induced dehydration stress. PLoS ONE 2017, 12. [CrossRef] [PubMed]

3. Huang, Z.; Zhong, X.-J.; He, J.; Jin, S.-H.; Guo, H.-D.; Yu, X.-F.; Zhou, Y.-J.; Li, X.; Ma, M.-D.; Chen, Q.-B.; et al. Genome-wide identification, characterization, and stress-responsive expression profiling of genes encoding lea (late embryogenesis abundant) proteins in moso bamboo (phyllostachys edulis). PLoS ONE 2016, 11, e0165953. [CrossRef] [PubMed] 
4. Dure, L., 3rd; Greenway, S.C.; Galau, G.A. Developmental biochemistry of cottonseed embryogenesis and germination: Changing messenger ribonucleic acid populations as shown by in vitro and in vivo protein synthesis. Biochemistry 1981, 20, 4162-4168. [CrossRef] [PubMed]

5. Wang, F.; Zhu, H.; Cheng, W.; Liu, Y.; Cheng, X.; Sun, J.; Gill, S.S.; Tuteja, N. Polyamines and fabiotic stress tolerance in plants. Plant Signal Behav. 2010, 5, 26-33.

6. Thomashow, M.F. Plant cold acclimation: Freezing tolerance genes and regulatory mechanisms. Annu. Rev. Plant Physiol. Plant Mol. Biol. 1999, 50, 571-599. [CrossRef] [PubMed]

7. Kikawada, T.; Nakahara, Y.; Kanamori, Y.; Iwata, K.-I.; Watanabe, M.; McGee, B.; Tunnacliffe, A.; Okuda, T. Dehydration-induced expression of lea proteins in an anhydrobiotic chironomid. Biochem. Biophys. Res. Commun. 2006, 348, 56-61. [CrossRef] [PubMed]

8. Hand, S.C.; Menze, M.A.; Toner, M.; Boswell, L.; Moore, D. Lea proteins during water stress: Not just for plants anymore. Annu. Rev. Physiol. 2011, 73, 115-134. [CrossRef] [PubMed]

9. Battaglia, M.; Olvera-Carrillo, Y.; Garciarrubio, A.; Campos, F.; Covarrubias, A.A. The enigmatic lea proteins and other hydrophilins. Plant Physiol. 2008, 148, 6-24. [CrossRef] [PubMed]

10. Boucher, V.; Buitink, J.; Lin, X.; Boudet, J.; Hoekstra, F.A.; Hundertmark, M.; Renard, D.; Leprince, O. Mtpm25 is an atypical hydrophobic late embryogenesis-abundant protein that dissociates cold and desiccation-aggregated proteins. Plant Cell Environ. 2010, 33, 418-430. [CrossRef] [PubMed]

11. Chakrabortee, S.; Tripathi, R.; Watson, M.; Schierle, G.S.; Kurniawan, D.P.; Kaminski, C.F.; Wise, M.J.; Tunnacliffe, A. Intrinsically disordered proteins as molecular shields. Mol. Biosyst. 2012, 8, 210-219. [CrossRef] [PubMed]

12. Olveracarrillo, Y.; Campos, F.; Reyes, J.L.; Garciarrubio, A.; Covarrubias, A.A. Functional analysis of the group 4 late embryogenesis abundant proteins reveals their relevance in the adaptive response during water deficit in arabidopsis. Plant Physiol. 2010, 154, 373-390. [CrossRef] [PubMed]

13. Finn, R.D.; Bateman, A.; Clements, J.; Coggill, P.; Eberhardt, R.Y.; Eddy, S.R.; Heger, A.; Hetherington, K.; Holm, L.; Mistry, J.; et al. Pfam: The protein families database. Nucleic Acids Res. 2014, 42, D222-D230. [CrossRef] [PubMed]

14. Bies-Etheve, N.; Gaubier-Comella, P.; Debures, A.; Lasserre, E.; Jobet, E.; Raynal, M.; Cooke, R.; Delseny, M. Inventory, evolution and expression profiling diversity of the lea (late embryogenesis abundant) protein gene family in arabidopsis thaliana. Plant Mol. Biol. 2008, 67, 107-124. [CrossRef] [PubMed]

15. Ciccarelli, F.D.; Bork, P. The Why Domain Mediates the Response to Desiccation in Plants and Bacteria; Oxford University Press: Oxford, UK, 2005; pp. 1304-1307.

16. Jaspard, E.; Hunault, G. Comparison of amino acids physico-chemical properties and usage of late embryogenesis abundant proteins, hydrophilins and why domain. PLoS ONE 2014, 9, e109570. [CrossRef] [PubMed]

17. Mouillon, J.-M.; Gustafsson, P.; Harryson, P. Structural investigation of disordered stress proteins. Comparison of full-length dehydrins with isolated peptides of their conserved segments. Plant Physiol. 2006, 141, 638-650. [CrossRef] [PubMed]

18. Tolleter, D.; Jaquinod, M.; Mangavel, C.; Passirani, C.; Saulnier, P.; Manon, S.; Teyssier, E.; Payet, N.; Avelange-Macherel, M.H.; Macherel, D. Structure and function of a mitochondrial late embryogenesis abundant protein are revealed by desiccation. Plant Cell 2007, 19, 1580-1589. [CrossRef] [PubMed]

19. Koag, M.-C.; Wilkens, S.; Fenton, R.D.; Resnik, J.; Vo, E.; Close, T.J. The k-segment of maize dhn1 mediates binding to anionic phospholipid vesicles and concomitant structural changes. Plant Physiol. 2009, 150, 1503-1514. [CrossRef] [PubMed]

20. Rahman, L.N.; Chen, L.; Nazim, S.; Bamm, V.V.; Yaish, M.W.; Moffatt, B.A.; Dutcher, J.R.; Harauz, G. Interactions of intrinsically disordered thellungiella salsuginea dehydrins tsdhn-1 and tsdhn-2 with membranes-synergistic effects of lipid composition and temperature on secondary structure. Biochem. Cell Biol. 2010, 88, 791-807. [CrossRef] [PubMed]

21. Liang, J.; Zhou, M.; Zhou, X.; Jin, Y.; Xu, M.; Lin, J. Jclea, a novel lea-like protein from jatropha curcas, confers a high level of tolerance to dehydration and salinity in arabidopsis thaliana. PLoS ONE 2014, 8, e83056. [CrossRef] [PubMed]

22. Zhang, J.; Kong, L.; Liu, Z.; Jahufer, Z.; Duan, Z.; Huo, Y.; Di, H.; Wang, Y. Stress-induced expression in arabidopsis with a dehydrin lea protein from cleistogenes songorica, a xerophytic desert grass. Plant Omics 2015, 8, 485-492. 
23. Waie, B.; Rajam, M.V. Effect of increased polyamine biosynthesis on stress responses in transgenic tobacco by introduction of human s -adenosylmethionine gene. Plant Sci. 2003, 164, 727-734. [CrossRef]

24. Zhang, J.; Duan, Z.; Zhang, D.; Zhang, J.; Di, H.; Wu, F.; Wang, Y. Co-transforming bar and cslea enhanced tolerance to drought and salt stress in transgenic alfalfa (medicago sativa 1.). Biochem. Biophys. Res. Commun. 2016, 472, 75-82. [CrossRef] [PubMed]

25. Gao, J.; Lan, T. Functional characterization of the late embryogenesis abundant (lea) protein gene family from pinus tabuliformis (pinaceae) in Escherichia coli. Sci. Rep. 2016, 6. [CrossRef] [PubMed]

26. Liu, Y.; Wang, L.; Xing, X.; Sun, L.; Pan, J.; Kong, X.; Zhang, M.; Li, D. Zmlea3, a multifunctional group 3 lea protein from maize (zea mays 1.), is involved in biotic and abiotic stresses. Plant Cell Physiol. 2013, 54, 944-959. [CrossRef] [PubMed]

27. Zhang, J.; John, U.P.; Wang, Y.; Li, X.; Gunawardana, D.; Polotnianka, R.M.; Spangenberg, G.C.; Nan, Z. Targeted mining of drought stress-responsive genes from est resources in Cleistogenes songorica. J. Plant Physiol. 2011, 168, 1844-1851. [CrossRef] [PubMed]

28. Hundertmark, M.; Hincha, D.K. Lea (late embryogenesis abundant) proteins and their encoding genes in Arabidopsis thaliana. BMC Genomics 2008, 9. [CrossRef] [PubMed]

29. Baker, J.; Dennsteele, C.V.; Iii, L.D. Sequence and characterization of 6 lea proteins and their genes from cotton. Plant Mol. Biol. 1988, 11, 277-291. [CrossRef] [PubMed]

30. Galau, G.A.; Wang, H.Y.; Hughes, D.W. Cotton Lea5 and Lea14 encode atypical late embryogenesis-abundant proteins. Plant Physiol. 1993, 101, 695-696. [CrossRef] [PubMed]

31. He, S.; Tan, L.; Hu, Z.; Chen, G.; Wang, G.; Hu, T. Molecular characterization and functional analysis by heterologous expression in e. Coli under diverse abiotic stresses for oslea5, the atypical hydrophobic lea protein from oryza sativa 1. Mol. Genet. Genom. 2012, 287, 39-54. [CrossRef] [PubMed]

32. Lan, T.; Gao, J.; Zeng, Q.Y. Genome-wide analysis of the lea (late embryogenesis abundant) protein gene family in Populus trichocarpa. Tree Genet. Genom. 2013, 9, 253-264. [CrossRef]

33. Cheng, F.; Wu, J.; Wang, X. Genome triplication drove the diversification of brassica plants. Hortic. Res. 2014, 1. [CrossRef] [PubMed]

34. Liang, Y.; Xiong, Z.; Zheng, J.; Xu, D.; Zhu, Z.; Xiang, J.; Gan, J.; Nadia, R.; Yin, Y.; Li, M. Genome-wide identification, structural analysis and new insights into late embryogenesis abundant (lea) gene family formation pattern in Brassica napus. Sci. Rep. 2016, 6. [CrossRef] [PubMed]

35. Yamaguchi-Shinozaki, K.; Shinozaki, K. Organization of cis-acting regulatory elements in osmotic- and cold-stress-responsive promoters. Trends Plant Sci. 2005, 10, 88-94. [CrossRef] [PubMed]

36. Wang, X.-S.; Zhu, H.-B.; Jin, G.-L.; Liu, H.-L.; Wu, W.-R.; Zhu, J. Genome-scale identification and analysis of lea genes in rice (oryza sativa 1.). Plant Sci. 2007, 172, 414-420. [CrossRef]

37. Li, X.; Cao, J. Late embryogenesis abundant (lea) gene family in maize: Identification, evolution, and expression profiles. Plant Mol. Biol. Rep. 2015, 34, 15-28. [CrossRef]

38. Lång, V.; Palva, E.T. The expression of a rab-related gene, rab18, is induced by abscisic acid during the cold acclimation process of arabidopsis thaliana (1.) heynh. Plant Mol. Boil. 1992, 20, 951-962. [CrossRef]

39. Zhu, Y.; Wang, B.; Tang, K.; Hsu, C.C.; Xie, S.; Du, H.; Yang, Y.; Tao, W.A.; Zhu, J.K. An Arabidopsis nucleoporin NUP85 modulates plant responses to ABA and salt stress. PLoS Genet. 2017, 13, e1007124. [CrossRef] [PubMed]

40. Kovacs, D.; Kalmar, E.; Torok, Z.; Tompa, P. Chaperone activity of erd10 and erd14, two disordered stress-related plant proteins. Plant Physiol. 2008, 147, 381-390. [CrossRef] [PubMed]

41. Eriksson, S.K.; Kutzer, M.; Procek, J.; Grobner, G.; Harryson, P. Tunable membrane binding of the intrinsically disordered dehydrin lti30, a cold-induced plant stress protein. Plant Cell 2011, 23, 2391-2404. [CrossRef] [PubMed]

42. Candat, A.; Macherel, D. The ubiquitous distribution of late embryogenesis abundant proteins across cell compartments in Arabidopsis offers tailored protection against abiotic stress. Plant Cell 2014, 26, 3148-3166. [CrossRef] [PubMed]

43. Hanin, M.; Brini, F.; Ebel, C.; Toda, Y.; Takeda, S.; Masmoudi, K. Plant dehydrins and stress tolerance: Versatile proteins for complex mechanisms. Plant Signal Behav. 2011, 6, 1503-1509. [CrossRef] [PubMed]

44. Close, T.J. Dehydrins: A commonalty in the response of plants to dehydration and low temperature. Physiologia Plantarum 1997, 100, 291-296. [CrossRef] 
45. Jiang, S.; Wang, J.; Liu, X.; Liu, Y.; Guo, C.; Zhang, L.; Han, J.; Wu, X.; Xue, D.; Gomaa, A.E.; et al. Drwh, a novel why domain-containing hydrophobic lea5c protein from deinococcus radiodurans, protects enzymatic activity under oxidative stress. Sci. Rep. 2017, 7. [CrossRef] [PubMed]

46. Franco-Zorrilla, J.M.; López-Vidriero, I.; Carrasco, J.L.; Godoy, M.; Vera, P.; Solano, R. DNA-binding specificities of plant transcription factors and their potential to define target genes. Proc. Nati. Acad. Sci. USA 2014, 111, 2367-2372. [CrossRef] [PubMed]

47. Kim, H.S.; Lee, J.H.; Kim, J.J.; Kim, C.H.; Jun, S.S.; Hong, Y.N. Molecular and functional characterization of CaLea6, the gene for a hydrophobic LEA protein from capsicum annuum. Gene 2005, 344, 115-123. [CrossRef] [PubMed]

48. Park, S.-C.; Kim, Y.-H.; Jeong, J.C.; Kim, C.Y.; Lee, H.-S.; Bang, J.-W.; Kwak, S.-S. Sweetpotato late embryogenesis abundant 14 (iblea14) gene influences lignification and increases osmotic- and salt stress-tolerance of transgenic calli. Planta 2011, 233, 621-634. [CrossRef] [PubMed]

49. Wang, M.; Li, P.; Li, C.; Pan, Y.; Jiang, X.; Zhu, D.; Zhao, Q.; Yu, J. SiLEA14, a novel atypical lea protein, confers abiotic stress resistance in foxtail millet. BMC Plant Biol. 2014, 14. [CrossRef] [PubMed]

50. Chiappetta, A.; Muto, A.; Bruno, L.; Woloszynska, M.; Lijsebettens, M.V.; Bitonti, M.B. A dehydrin gene isolated from feral olive enhances drought tolerance in arabidopsis transgenic plants. Front. Plant Sci. 2015, 6. [CrossRef] [PubMed]

51. Brini, F.; Hanin, M.; Lumbreras, V.; Amara, I.; Khoudi, H.; Hassairi, A.; Pages, M.; Masmoudi, K. Overexpression of wheat dehydrin dhn-5 enhances tolerance to salt and osmotic stress in Arabidopsis thaliana. Plant Cell Rep. 2007, 26, 2017-2026. [CrossRef] [PubMed]

52. Finn, R.D.; Mistry, J.; Tate, J.; Coggill, P.; Heger, A.; Pollington, J.E.; Gavin, O.L.; Gunasekaran, P.; Ceric, G.; Forslund, K.; et al. The pfam protein families database. Nucleic Acids Res. 2010, 38, D211-D222. [CrossRef] [PubMed]

53. Altschul, S.F.; Gish, W.; Miller, W.; Myers, E.W.; Lipman, D.J. Basic local alignment search tool. J. Mol. Biol. 1990, 215, 403-410. [CrossRef]

54. Letunic, I.; Copley, R.R.; Schmidt, S.; Ciccarelli, F.D.; Doerks, T.; Schultz, J.; Ponting, C.P.; Bork, P. Smart 4.0: Towards genomic data integration. Nucleic Acids Res. 2004, 32, D142-D144. [CrossRef] [PubMed]

55. Marchler-Bauer, A.; Derbyshire, M.K.; Gonzales, N.R.; Lu, S.; Chitsaz, F.; Geer, L.Y.; Geer, R.C.; He, J.; Gwadz, M.; Hurwitz, D.I.; et al. Cdd: Ncbi's conserved domain database. Nucleic Acids Res. 2015, 43, D222-D226. [CrossRef] [PubMed]

56. Feng, D.-F.; Doolittle, R.F. Progressive sequence alignment as a prerequisitetto correct phylogenetic trees. J. Mol. Evol. 1987, 25, 351-360. [CrossRef] [PubMed]

57. Tamura, K.; Stecher, G.; Peterson, D.; Filipski, A.; Kumar, S. Mega6: Molecular evolutionary genetics analysis version 6.0. Mol. Biol. Evol. 2013, 30, 2725-2729. [CrossRef] [PubMed]

58. Higgins, D.G.; Sharp, P.M. Clustal: A package for performing multiple sequence alignment on a microcomputer. Gene 1988, 73, 237-244. [CrossRef]

59. Gasteiger, E.; Gattiker, A.; Hoogland, C.; Ivanyi, I.; Appel, R.D.; Bairoch, A. Expasy: The proteomics server for in-depth protein knowledge and analysis. Nucleic Acids Res. 2003, 31, 3784-3788. [CrossRef] [PubMed]

60. Emanuelsson, O.; Brunak, S.; von Heijne, G.; Nielsen, H. Locating proteins in the cell using targetp, signalp and related tools. Nat. Protoc. 2007, 2, 953-971. [CrossRef] [PubMed]

61. Bailey, T.L.; Boden, M.; Buske, F.A.; Frith, M.; Grant, C.E.; Clementi, L.; Ren, J.; Li, W.W.; Noble, W.S. Meme suite: Tools for motif discovery and searching. Nucleic Acids Res. 2009, 37, W202-W208. [CrossRef] [PubMed]

62. Rombauts, S.; Dehais, P.; Van Montagu, M.; Rouze, P. Plantcare, a plant cis-acting regulatory element database. Nucleic Acids Res. 1999, 27, 295-296. [CrossRef] [PubMed]

63. Yue, R.; Lu, C.; Sun, T.; Peng, T.; Han, X.; Qi, J.; Yan, S.; Tie, S. Identification and expression profiling analysis of calmodulin-binding transcription activator genes in maize (Zea mays L.) under abiotic and biotic stresses. Front. Plant Sci. 2015, 6. [CrossRef] [PubMed]

64. Petrov, V.; Vermeirssen, V.; De, C.I.; Van, B.F.; Minkov, I.; Vandepoele, K.; Gechev, T.S. Identification of cis-regulatory elements specific for different types of reactive oxygen species in arabidopsis thaliana. Gene 2012, 499, 52-60. [CrossRef] [PubMed] 
65. Passricha, N.; Saifi, S.; Ansari, M.W.; Tuteja, N. Prediction and validation of cis-regulatory elements in 5' upstream regulatory regions of lectin receptor-like kinase gene family in rice. Protoplasma 2017, 254, 669-684. [CrossRef] [PubMed]

66. Acharya, B.R.; Jeon, B.W.; Zhang, W.; Assmann, S.M. Open stomata 1 (OST1) is limiting in abscisic acid responses of arabidopsis guard cells. New Phytol. 2013, 200, 1049-1063. [CrossRef] [PubMed]

67. Trapnell, C.; Pachter, L.; Salzberg, S.L. Tophat: Discovering splice junctions with RNA-seq. Bioinformatics 2009, 25, 1105-1111. [CrossRef] [PubMed]

68. Trapnell, C.; Roberts, A.; Goff, L.; Pertea, G.; Kim, D.; Kelley, D.R.; Pimentel, H.; Salzberg, S.L.; Rinn, J.L.; Pachter, L. Differential gene and transcript expression analysis of rna-seq experiments with tophat and cufflinks. Nat. Protoc. 2012, 7. [CrossRef] [PubMed]

69. Wang, L.; Feng, Z.; Wang, X.; Wang, X.; Zhang, X. Degseq: An r package for identifying differentially expressed genes from rna-seq data. Bioinformatics 2010, 26, 136-138. [CrossRef] [PubMed]

70. Deng, W.; Wang, Y.; Liu, Z.; Cheng, H.; Xue, Y. Hemi: A toolkit for illustrating heatmaps. PLoS ONE 2014, 9, e111988. [CrossRef] [PubMed]

71. Fujisawa, M.; Takita, E.; Harada, H.; Sakurai, N.; Suzuki, H.; Ohyama, K.; Shibata, D.; Misawa, N. Pathway engineering of brassica napus seeds using multiple key enzyme genes involved in ketocarotenoid formation. J. Exp. Bot. 2009, 60, 1319-1332. [CrossRef] [PubMed]

(c) 2018 by the authors. Licensee MDPI, Basel, Switzerland. This article is an open access article distributed under the terms and conditions of the Creative Commons Attribution (CC BY) license (http://creativecommons.org/licenses/by/4.0/). 